\title{
Editorial
}

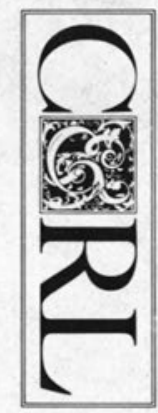

\section{$C \mathcal{E} R L$ 's New Editor}

With this issue of College $\mathcal{E}$ Research Libraries-my twenty-first-I complete my term as editor and pass the mantle of responsibility to my successor, Charles Martell.

I am honored to have been asked to serve the profession in this capacity and have acquired from this service, among other things, a deep appreciation for the work that editors do, an appreciation that will inform my reading of librarianship journals in the years to come. Charles will put his own imprint on CERL, and I look forward to lively reading from his editorship.

A word about this issue. The articles included offer different perspectives on a single theme-the impact of information and its associated technologies on academic libraries and librarianship. Arms discusses the convergence of function between the computing center and the library. Battin describes the structural changes in organization that universities face as the species library becomes a generic function. Stoffle and her colleagues discuss the role of the library in the microcomputer revolution and argue that the library is the most appropriate center for serving the revolutionaries. Matheson and Adams, in different ways, address the role of librarians and the book in the information age. In reviewing his father's concern about librarians and books, Adams connects eras in a timeless and generic way. English enriches the discussion by reporting on a survey of administrators' perceptions of librarians and faculty status. And finally, we have the report of the symposium at Cornell on collections.

An agenda of issues worthy of the best our profession can deliver emerges clearly from these pieces. Adams captures the essential notion when he concludes that "it is change we are dealing with. ..."'Indeed! 


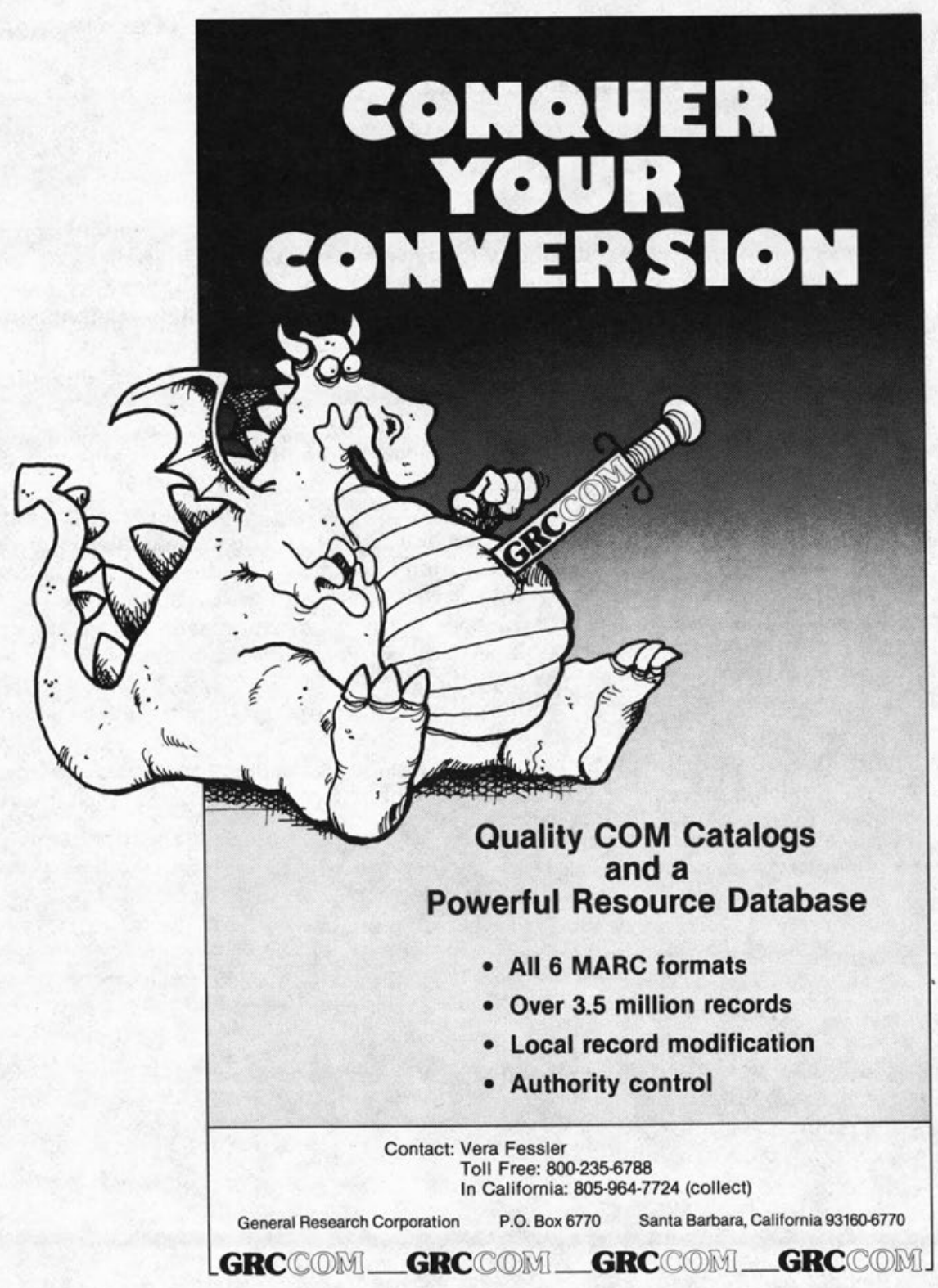

